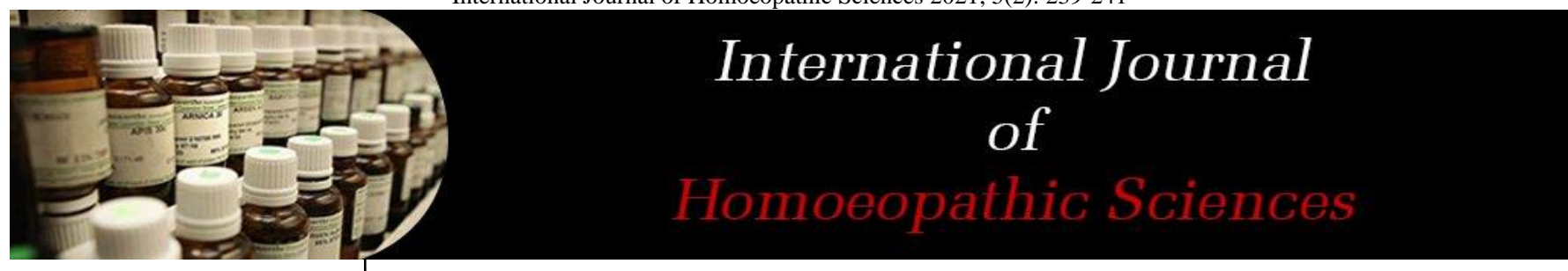

E-ISSN: 2616-4493

P-ISSN: 2616-4485

www.homoeopathicjournal.com IJHS 2021; 5(2): 239-241

Received: 19-01-2021

Accepted: 21-03-2021

Arti Lavhe

PG Student, Department of

Pharmacy, Gurumishri

Homeopathic Medical College,

Shelgaon, Jalna, Maharashtra,

India

Kavita Khandare

Professor \& P.G. Guide,

Department of Pharmacy,

Gurumishri Homeopathic

Medical College, Shelgaon,

Jalna, Maharashtra, India
Corresponding Author:

Arti Lavhe

PG Student, Department of

Pharmacy, Gurumishri

Homeopathic Medical College,

Shelgaon, Jalna, Maharashtra

India

\title{
Homoeopathic approach towards skin diseases like acne vulgaris
}

Arti Lavhe and Kavita Khandare

DOI: https://doi.org/10.33545/26164485.2021.v5.i2d.389

\begin{abstract}
Our Skin is the most beautiful covering of human body and everybody are very sensitive to their skin specially women in our society. acne is an inflammatory and multifactorial skin disease. Different external and internal factors, including air pollution, aggressive skin products, medication, mechanical and hormonal factors and more recently life style and stress have been suggested as having an impact on acne. Acne vulgaris is a disorder of hair-bearing skin in which hair follicles develop obstructing horny plugs (comedones) as a result of which inflammation later develops around the obstructed follicles, causing tissue destruction and scar formation. Acne affects sebaceous follicles; these areas include the face, the upper part of the chest, and the back.
\end{abstract}

Keywords: homoeopathic approach, skin diseases like, acne vulgaris

\section{Introduction}

Acne vulgaris is an extremely common disease with some $70 \%$ of the population developing some clinically evident acne at some point during adolescence and early changes affect many teenagers in both sexes but peak age of severity in female is 16 to 17 years and in male 17 to 19 years just after puberty The management of such infections or any other dermatological condition by modern medicine comprises a local approach with the help of prescription of external applications and Steroids as they considers as these are the local ailments and concentrate on that area only. But Homoeopathy is unique system of medicine which considers man as whole. Therefore it emphasizes that there are no any local diseases but local maladies which are developed due to internal derangement of vital force expressed outward at local part. The synonyms for acne are Pimples; in Hindustani: Kil, Muhase. In Marathi : Murum Acne vulgaris is a disorder of hair-bearing skin in which hair follicles develop obstructing horny plugs (comedones) as a result of which inflammation later develops around the obstructed follicles, causing tissue destruction and scar formation. Acne is characterized by areas of skin with seborrhea is scaly red skin comedones, blackheads and whiteheads, papules is pinheads pustules or pimples. Nodules (large papules) and possibly scarring. Acne affects sebaceous follicles; these areas include the face, the upper part of the chest, and the back. Severe acne is inflammatory, but acne can also be in inflammatory forms. caused changes in pilosebaceous units, skin structures consisting of a hair follicle and its associated sebaceous gland, changes affect many teenagers in both sexes but peak age of severity in female is 16 to 17 years and in male 17 to 19 years just after puberty the comedians progress to papules many factors rather than single androgen surge in its production during puberty and adolescents because increased Stimulations of sebaceous gland activity and increase in testosterone, which people of both genders during puberty. For most people, acne diminish over time or at the very least decrease after one reach one's early twenties. There is, however, no way to predict how long it will take to disappear entirely, and some individuals will carry this condition well into their thirties,forties, and beyond. Adolescent and young adult are typically affected. side generally affecting the face, on upper chest and back, rarely buttocks and thighs.

local signs and symptoms of acne vulgaris include pain tenderness itching and erythema of legion scaring.

Acne vulgaris may have psychological impact on any patient regardless of severity or the grade of disease pt often have problem with self esteem self confidence social withdrawal and depression, anger, Aside from scarring, its main effects are psychological, acne patient 
experience shame, embracement and lack of confidence such as reduced self esteem impaired social contact and underemployment severe acne may be related to increased danger and anxiety and in very extreme cases there may be depression or suicide. Acne usually appears during adolescence, when people already socially insecure. Early and aggressive treatment is therefore advocated by some to lessen the overall long-term A high glycemic load diet is associate with worsening acne. also the consumption of milk salt chocolate and, products with these ingredients often contain a high glycemic load.

In this type of scenario, homoeopathy can play an effective role in the management of Acne vulgaris. It acts in a holistic manner catering to all the spheres of an individual. Holism implies that the parts in a system relate interactively; that body, mind and spirit are all aspects of a whole being.

Dr. Roberts had mentioned in his quote that-

"Homoeopathy treats the sick individual: it is therefore a specialty". Homoeopathy considers the man as a whole, not just his individual parts. Therefore, primarily homoeopathy has less appeal for the man of mechanical bent, for it is this man who makes the best surgeon. Instead, homoeopathy offers a gentler way toward health of the entire individual. Homoeopathy seeks to relieve the individual as much as possible from the heavy burden of the hereditary tendencies he carries, and to guard against increasing this load by enabling his vital energy to provide its own immunity against disease."

Also this study is done to see the effect of homoeopathic medicines in cases of Acne vulgaris without using any kind of external application as Dr. Samuel Hahnemann in his sixth edition of Organon of Medicine had guided against the use of external application for diseases caused due to dynamic cause.

In aphorism no.194 he said that- " It is not useful, either in acute local diseases of recent origin or in local affections that have already existed a long time, to rub in or apply externally to the spot an external remedy, even though it be the specific and, when used internally, salutary by reason of its homoeopathicity, even although it should be at the same time administered internally; for the acute topical affections(e.g. inflammations of individual parts, erysipelas, etc.) which have not been caused by external injury of proportionate violence, but by dynamic or internal causes," As Acne vulgaris is mostly caused due to an internal imbalance such as hormonal imbalances or due to heredity, therefore, it needs to be addressed with a polychrest remedy which can act as a chronic constitutional remedy when indicated. This will help in curing the patient permanently as against suppression by use of topical application. Homoeopathy treatment not only limit itself to controlling the acute manifestation of symptoms but stimulates individual's own natural forces of recovery by aiming treatment homoeopathy can play very effective role in the treatment of acne this system provide a holistic approach to individual and strengthen the immune system causing healing from within outwards homoeopathy takes into account the root cause of disease as an imbalance of vital force it then restore this balance by gently stimulating the body to naturally complete its healing process with the indicated remedy

Homoeopathy is a science of therapeutics which helps to restore the sick to health by administering medicine based on the principle of SIMILIA SIMILIBUS CURENTUR - let like be cured by likes. Acne vulgaris is an external presentation of an internal disorder due to lowered vitality and immunity. Homoeopathy does not believe in treating any skin diseases by simply applying ointment or creams.: Dr. Samuel Hahnemann quotes: The Psora is the only cause of all the several diseases of mankind; or in other words, this Psora is the only disease, while all the so called diseases, having all the different shapes \& names, are its different expressions.

There are three basic miasms affecting the integumentary system: psora, sycosis \& syphilis. Miasmas lie dormant in a person's genetic make up until a pre-encoded trigger is activated by the occurrence of something contraindicated to that individual's maintenance of well-being. These triggers are most commonly a trauma or intervention of some kind that affects the person's physical or mental status. Here it can be seen that the basic emotions of anger \& resentment, grief \& guilt and inability to let go, are major keys to the resolution of skin problems. Recent works on emotion has revealed the fact that, it can cause various psychosomatic illnesses, which has been postulated by Hahnemann long before the birth of scientific psychology. The importance of emotional reaction has been associated with a number of illnesses like peptic ulcers, diabetes, hypertension, skin eruption, etc

The skin is the mirror in which nature reflects at the earliest certain disorders taking place inside the body. So skin diseases can be considered as external manifestations of internal disorders. It is a timely hint for us to find out the cause and treat the original focus. Instead what we see and find today is that no sooner any eruptions appear on the skin a serious attempt is made to suppress the same. The founder of homoeopathy had observed it, understood it, and warned against such harmful procedure a century and a half ago.

According to J. H. Allen,- All skin eruptions are either secondary or tertiary expressions of miasmatic actions. The skin is the mirror or the reflector of the internal stress, the internal dynamics \& the internal workings of this human machine. It has, in the skin its reflection, its kaleidoscope, its kinetoscopic views of its internal movements \& its multiple shading of disease; its lights \& its shadows that goes to make up a picture thrown upon that human canvas. The skin shows much of the perverted life action in the organism.

\section{References}

1. Homoeopathy and the Skin' by Dr. W.L Balfour, Homoeopathic Heritage ISSN- 9070-6038, published in January 2016;41(10):44

2. An Illustrated Handbook of Skin Diseases And Sexually Transmitted Infections By Dr Uday Khopkar, Bhalani Book Depot, Chapter 10, 109

3. Aphorism Organon of Medicine by Samuel Hahnemann, Sixth edition, Indian books \& Periodicals Publishers, 194, 221-222.

4. Banerjee Dr. DD Augmented Textbook of HOMOEOPATHIC PHARMACY; 2ndedn; B.Jain Publishers (P) Ltd; 2006;78(55):309-449.

5. Banerjee NK, Singha N. Treatise on Homoeopathic Pharmacy, New Delhi, B. Jain Publishers (P) Ltd., reprint edition 2001

6. Boenninghausens Therapeautics pocket Book By Dr T.F. Allen B Jain publications pvt ltd, 221 
7. Boericke O. New Manual of Homoeopathic Materia Medica with Repertory. 3rd Revised \& Augmented edition. New Delhi. B. Jain Publishers Pvt. Ltd, 2010

8. Close, Stuart. The Genius of Homoeopathy - Lectures and Essays on Homoeopathic Philosophy. Reprint edition. New Delhi. B. Jain Publishers Pvt. Ltd 2016. 71.

9. Davidson's Principles and Practice of Medicine, $19^{\text {th }}$ Edition, 21, 1082.

10. Dr. Mahmood NF, Shipman AR. Age old problem of acne in Inernatonal Journal of womens Dermatology

11. Dr. Dhiraj Kakkar, External application in clinical practice, NarayanaVerlag GmbH, Blumenplatz 2, D79400 Kandern, Germany.

12. Dr. Compton Burnett J. (MD). Diseases of the Skin. New Delhi. B. Jain Publishers Pvt Ltd. 2014. 73. Robin Murphy. Homoeopathic Medical Repertory. 3rd revised edition. New Delhi. B. Jain Large Print, 2010.

13. Essentials of Medical Physiology, $5^{\text {th }}$ edition, Jaypee publishers, Section-5, 334-339.

14. Genius of homoeopathy Lectures and Essays on homoeopathic philosophy second edition by Stuart close chapter 13,237

15. Homoeopathy In Acne \& Alopecia, By Dr. P.S Rawat, Reprint Edition IS81-7021-477-7, B. Jain Publishers, 1994, 10.

16. Homoeopathy in Skin Diseases by Dr S.R. Wadia, Fourth edition B. Jain publishers, 1983, 6.

17. International Journal of Science and Research (IJSR) ISSN (Online): 2319-7064 Index Copernicus Value (2015): 78.96 | Impact Factor 2015;6:391

18. Leaders in Homoeopathy Theapeutics By E.B Nash Bjain publication NAT MUR, 325

19. Lecture On Homoeopathic Philosophy James Tyler Kent. Adi, B. S., Adi, G. B., \& Tanuja, B. A comparison of efficacy of Plantago major and Calendula officinalis in the management of gingivitis: a randomized controlled clinical trial. International Journal of Alternative and Complementary Medicine, 2020;1-7:153.

20. Roxburgh's Common Skin Diseases, fourteenth Edition, Chapman \& Hall, Chapter 10, 257

21. Roberts HA. The principles and Art of cure by Homoeopathy; Reprint edition; New Delhi. B. Jain Publishers Pvt. Ltd 2017, 72.

22. Roger Van Zandvoort. The Complete Repertory: Mind to Generalities (All in One). Holland. IRHIS 1996.

23. Rules of Adolescence- Role of Homoeopathy by Dr. Shiv Dua, National Journal of Homoeopathy 2014;16(4).

24. Sahani Dr. MK, Principles and Practice of Homoeopathic PHARMACY for students; 1 stedn; B.Jain Publishers (P) Ltd 2007, 6-8.

25. Sarkar BK. Organon of Medicine; Section-6:- A True Practitioner of the Healing Art should be an Unprejudiced Observer; Reprint Edition-2003-2004.

26. The Principles and Art of Cure by Homoeopathy by H.A. Roberts, B. Jain publishers, Chap-1, 15.

27. Essentials of Medical Physiology, $5^{\text {th }}$ edition, Jaypee publishers, Section-5, 334-339.

28. Genius of homoeopathy Lectures and Essays on homoeopathic philosophy second edition by Stuart close chapter 13,237

29. Hahnemann. Organon of Medicine, Para 186,193 to
203,B Jain publishers Pvt. Ldt. 1833, 1991 